\title{
Anti-money laundering in the United Kingdom: new directions for a more effective regime
}

\begin{tabular}{|r|l|}
\hline Journal: & Journal of Money Laundering Control \\
\hline Manuscript ID & JMLC-04-2021-0041 \\
\hline Manuscript Type: & Scholarly Article \\
\hline Keywords: & $\begin{array}{l}\text { money-laundering, financial crime, economic crime, organised crime, } \\
\text { effectiveness, compliance }\end{array}$ \\
\hline \multicolumn{2}{|l}{} \\
\hline
\end{tabular}

\section{SCHOLARONE ${ }^{\text {m }}$}

Manuscripts 


\title{
Anti-money laundering in the United Kingdom: new directions for a more effective regime
}

\begin{abstract}
Purpose: To provide a more nuanced understanding of the effectiveness of the anti-money laundering (AML) regime in the UK and explore opportunities to improve policy and performance.

Design/methodology/approach: Qualitative research design using semi-structured interviews and a focus group with practitioners from both public and private sectors.

Findings: We identify preventive measures are underfunded by the public sector; there is a disconnect between the regulatory requirement and the regulators' supervisory approach leading to the ineffective application of the risk-based approach; and authorities have limited ability to stop low-utility reports. Increased collaboration across institutions and sectors, better utilisation of innovative technologies and a sustainable funding plan are needed to drive a collective response to money laundering.
\end{abstract}

Originality: We present new data from AML practitioners to provide better understanding of the limitations of the AML regime in the UK.

Research limitations/implications: Few practitioners in the industry have the knowledge and expertise to discuss the topic at a strategic level and participants were limited $(n=8)$.

Practical implications: We add to the growing corpus of research showing that the anti-money laundering regime in the UK is ineffective and needs reform.

Social implications: We encourage practitioners to improve the AML regime, this research contributes with the reform of the existing measures against financial crime.

Keywords: Money-laundering, financial crime, economic crime, organised crime, effectiveness, compliance.

Article classification: Research Paper 


\section{Introduction}

Money laundering is an intangible process used to disguise the unlawful origin of profits generated by criminal activities. While perceived to be a victimless crime, it is most often connected to a range of violent and exploitative crimes, such as large scale drug dealing and human trafficking. Further, in the UK, money laundering has been estimated to exceed $£ 90$ billion a year (Home Office, 2017); representing 4-5\% of the UK's GDP (Office for National Statistics, 2021).

Since the creation of the Financial Action Task Force (FATF), more than 30 years ago, public and private institutions have been working on developing controls to detect suspicious activities relating to money laundering. Presently, these controls exist within a linear system where the private sector, mostly financial institutions, act as the gatekeepers for these activities and have the responsibility to file Suspicious Activity Reports (SAR) to Financial Intelligence Units (FIUs) whenever a suspected case is identified.

However, fines for non-compliance with the required anti-money laundering rules have increased. In $2019, \$ 8.14$ billion of fines were imposed for a total of 58 anti-money laundering breaches in the UK (Burns, 2020). In fact, SARs, which are meant to stop money laundering, instead allows it to flourish. Evidence suggests financial institutions file SARs to immunise themselves against sanctions and criminal prosecution, which means that they can be used as a free pass to keep moving dirty money and collecting fees. Financial institutions file SARs about a huge array of transactions, but they often do nothing to halt them. Further, because SARs are a type of confidential reporting, there is limited transparency about what FIUs and Law Enforcement Agencies (LEAs) do with them. Investigating all or none of them is entirely at the discretion of the institution who receives the report.

There is also limited empirical evidence that the SAR process is effective in preventing money laundering. In this paper, therefore, we critically investigate the inefficiencies of the existing AML framework to provide a more nuanced understanding of key points of ineffectiveness in the UK's AML regime. We also explore policy actions that could help to address these issues in a more targeted manner to generate more significant results in a shorter period of time.

\section{The (in)effectiveness of AML}

Historically, the objectives of the AML regime have not been clearly articulated or understood, and different interpretations of its intent have made the measurement of effectiveness difficult (Turkington, 2019). Various attempts to understand the extent of the money laundering problem have been made, but, due to a lack of data, there is still a general inability to agree on appropriate indicators to assess the (in)effectiveness of the existing regime. 
The most common form of assessment of effectiveness is performed by the FATF. The FATF effectiveness criteria, however, are based on the lowest common denominator of its members, which means that a good rank in the evaluations does not mean that the country has effective controls. This form of comparative assessment has limited efficacy to understand effectiveness. Under the current assessment system, comparing well, unfortunately, does not mean success because, as summarised by David Lewis in 2020, "everyone is doing badly, but some are doing less badly than others" (Bowers, 2020). Effectiveness evaluations also lack consistent and systematic data analysis. Claims made by these assessments on whether countries have less or more effective systems will naturally be open to allegations of ad-hoc, impressionistic or politicised judgments (Levi et al., 2018).

The key issue hindering a more systematic analysis of effectiveness is its dependency on the estimate of a variable that is difficult to obtain, the total amount of money being laundered. There are no credible estimates either of the total amount laundered (globally or nationally) nor of the predicate offences that AML aims to prevent (Levi et al., 2018). A study conducted by Moiseienko and Keatinge (2019) concluded that despite the inability of governments or researchers to produce a comprehensive estimate of money laundering, the lower bounds of the scale of money laundering can be measured based on the aggregation of the volume of proceeds that are generated by various types of crime.

Few attempts have been made based on this approach; using the interdiction rate - the proportion of illicit funds seized or forfeited - as a proxy indicator for the effectiveness of AML (see reports published by The United Nations Office on Drugs and Crime, 2011; European Police Office, 2016; Pol, 2018). Hopkins and Shelton (2019) has argued against this approach, stating that the measurement of the AML's effectiveness should be less focused on the confiscation of illicit assets, and more focused on the identification and closure of opportunities for money laundering. By seizing illicit assets, AML is reducing opportunities for money laundering and, therefore, indicators based on the amount of illicit funds being seized should inform on the effectiveness of AML measures.

When it comes to the UK's AML regime, the last mutual evaluation conducted by the FATF was in 2018 (FATF, 2018), and the outcomes of the evaluation classified the UK as the most effective country when compared to the other 101 countries that were evaluated.

Conversely, the interdiction rate in the EU (UK included) between 2010 and 2014 was not higher than 2\% (United Nations Office on Drugs and Crime, 2011; European Police Office, 2016; Pol, 2018). A simple calculation based on public information reveals a similar rate. The scale of organised crime in the UK was estimated to be approximately $£ 13$ billion between 2015 and 2016 (Fell et al., 2019). Between 2016 and 2017, £216 million, less than $2 \%$ of the estimate of the scale of organised crime in the previous year, was recovered using the Proceeds of Crime Act 2020 (POCA) (FATF, 2018). 
An AML regime that leaves more than $98 \%$ of criminal funds in criminal hands cannot be considered effective. Four issues have been consistently raised in articles as the root causes for the ineffectiveness of the UK's AML regime: (1) the compliance culture; (2) the inefficiency of the existing AML process; (3) the fragmentation of information across institutions and sectors; and (4) the authorities inability to process reports.

The first issue relates to the compliance-orientated approach, which became a set of measures that, for the most part, focused on making regulators happy without effectively combating money laundering (McGarvey, 2013; Jakobi, 2018). This approach achieved a life of its own and started to fail to reach its own original goals (Geiger and Wuensch, 2007). The underlying assumption of causality between compliance with the AML regulation and the reduction of money laundering is incorrect (Turkington, 2019). AML controls have been driven by the fear of being seen as being non compliant with the regulations (Huang, 2015). Financial institutions have been focused on self-preservation over combating crime. The consequence of this is that institutions divert resources to satisfy the regulator's requirements, even where they believe that these would be unlikely to yield tangible prevention of money laundering (Redhead, 2019). In this way, AML is considered to be a burden for banks. The costs outweigh the benefits (Balani, 2019); creating a burden for legitimate businesses, i.e. banks, because it does not effectively reduce money laundering. It is considered to penalise legitimate business while illicit activities continue to prosper without disruption.

The second issue relates to the inefficiency of the existing AML processes. In the UK, banks alone collectively spend approximately $£ 5$ billion on AML per year (BBA, 2016). Most of this investment is directed towards transaction monitoring technology and operations, which is a process that has longstanding efficiency issues. Despite the high cost of implementing and maintaining the technologies and operations required to support the process, on average, $85 \%$ of the alerts generated by systems are closed by analysts as false positives. Financial Institutions, however, continue to focus on transaction monitoring because this is required by regulators (McGowan, 2017).

The third issue relates to the limitations in the process whereby the public and private sectors share information. Evidence suggests that despite the creation of public-private partnerships, such as the JMLIT, the public-private information sharing process between financial institutions and LEAs is slow and has multiple frictions that hinder the identification and disruption of financial crime (Maxwell, 2019). Regulations do not incentivise information to be shared in two ways. Regulators require FIs to share their information with public authorities, but none of them require governments to share information in their possession, leaving financial institutions to search for suspicious activity "in the dark" (Kang, 2018). To eliminate the frictions in the process and enable the implementation of a more systematic and scalable mechanism to share information, data needs to be harmonised across institutions. A harmonised and consistent framework for datasets should make it possible for institutions 
to share their data with other members of the partnerships, thus enabling the consolidation of data and a more holistic analysis of customers' behaviours (Delle-Case and Bailey, 2018)..

The authorities' inability to process reports is the fourth issue. According to FIU representatives and former senior officials in the UK, no more than $3 \%$ of the SARs are of immediate value to investigations (Redhead, 2019). The FIU has a fundamental role in the regime, which is as effective as the authorities' ability to investigate reports. If reports are not investigated and cases are not brought to justice, most of the criminals can simply continue to conceal their activities without disruption. The FATF's mutual evaluation report also revealed that the UKFIU is under-resourced, which reinforces the idea that it doesn't have the required capabilities to investigate the cases it receives (FATF, 2018).

\section{Methods}

\section{Research design}

This study used a qualitative research design. This approach was selected because it was the most appropriate method to collect and analyse new data from (hard to reach) industry experts and practitioners who understand the AML regime in the UK. This study collected data from participants' observations to provide a new and more nuanced understanding of the AML regime in the UK. This study design was broadly interpretivist because it sought to amalgamate expert opinions from individuals who have a range of experiences and who observe the AML regime from different perspectives.

\section{Data collection and analysis}

Data were collected using semi-structured interviews and focus groups. Semi-structured interviews were selected to give participants the opportunity to provide data not limited to answering the predefined questions. The semi structured interviews were supported by questionnaires that were organised in eight areas, namely: process, information, technology, people, guidance, reform, and initiatives coordination. Some questions in the questionnaire were adjusted to the sector of the interviewee, so that they were set in the right context for the conversation. The questionnaires were reviewed by two subject matter experts who did not participate in the interviews. All interviews were conducted in 2019, and the roles of the interviewees were: (1) think tank researcher; (2) banking association director; (3) UK Government ministerial department director; (4) money service business director; (5) financial crime director in a large UK bank; (6) financial crime lead and MLRO of a multinational bank; (7) partner in an international accounting firm; (8) real estate association director. 
A focus group session was held on 25 November 2019 to share early results of the research. In this session, findings were presented to a group of 13 practitioners. Participants included senior representatives from large banks, think-tanks, the gambling association, and the UK government.

\section{Data analysis}

Once all the interviews and the focus session had been completed, the recordings of the interviews were transcribed to a spreadsheet that organised the participants' input into a matrix with the eight key areas described in Section 3.2.1 as columns, and the participants as rows. The transcripts were analysed using a bottom-up approach, where the arguments made by the participants were consolidated into six key findings, as follows.

\section{Results}

Six key findings were revealed by this research, namely: (1) financial institutions do not effectively apply a risk-based approach; (2) innovation has resulted in low return on investments; (3) information is not shared at scale and partnerships are not inclusive; (4) AML is not evolving uniformly across sectors; (5) LEAs have not been stopping low-utility reports and are not guiding FIs to focus resources on relevant cases of investigation; and (6) incremental adjustments will not improve the effectiveness of the regime; a sustainable funding plan is required to drive a major transformation.

\section{Financial institutions do not effectively apply a risk-based approach}

Despite the requirement for FIs to adopt a risk-based approach to develop their AML controls, evidence suggests in practice, it does not happen. FIs avoid adopting the risk-based approach because of the consequences of jumping to wrong conclusions:

"Firms are mostly away from the risk-based approach, because of the consequences of getting it wrong. If you make a wrong risk decision, even if the intentions were right and it was wellthought-through, there could be personal and institutional consequences, so why use a riskbased approach? People talk about the risk-based approach, but in reality, they just tick the boxes" (Interviewee 6, 2019)

"If MLROs could effectively apply the risk-based approach, they would stop transaction monitoring and use different data and analytics solutions. Regulators would not accept the riskbased approach as an explanation for this decision though" (Interviewee 6, 2019)

\section{Innovation has resulted in low return on investments}


We observed a level of frustration with the return on investment made by FIs in innovation. Despite the expectations that advanced technologies, such as machine-learning, are indispensable to process the increasingly large amount of data being generated by transactions, the benefits of these initiatives have not been realised to date:

"There is a lot of money being put into emerging technology capability in the private sector. We are not, however, harnessing the benefits of it. There is a high cost to build emerging technology into the existing systems" (Interviewee 2, 2019)

A key issue undermining the adoption of machine learning is the inability to explain its outcomes to regulators. FIs and regulators have not agreed on an approach to solve this issue and have not communicated a homogeneous view of the challenges hindering the adoption of these technologies:

"There is a lack of belief that machine learning solutions can replicate the triage done by investigators. The problem of machine learning is why the machine generates a certain outcome - this would be important to demonstrate the rationale to regulators" (Interviewee 3, 2019)

"There is a need to get the dialogue right between the financial sector and the regulators. There is a lack of clarity on whether there is permission to use these technologies; the issues related to the use of these technologies remain unclear. Banks don't have a single homogeneous view of the truth" (Interviewee 3, 2019)

Further, there is an issue relating to education. Regulators and LEAs do not have sufficient knowledge about more advanced technology. This lack of awareness has been driving continued reinforcement of outdated approaches to regulated entities and undermining the investments made by the private sector in more advanced technology.

"LEAs and Regulators are not updated in terms of the advances that have been made in analytics. The banks are much more advanced than what the regulators can understand" (Interviewee 5, 2019)

There is some evidence that innovation has also been driven by cost reduction and focuses on parts of the process that have a higher cost but low value.

"There is an opportunity to use machine learning to automate the first level; however, by automating this stage of the process the bank will be automating activities that do not add significant value to the process" (Interviewee 5, 2019)

\section{Information is not shared at scale and partnerships are not inclusive}


The third key finding relates to the fact that information is not shared at scale and partnerships are not inclusive of all sectors because banks detect and analyse money laundering cases in isolation.

"Banks need to move out from silos to have more general power to share information and intelligence, particularly allowing the private sector to share information between themselves to detect financial crime" (Interviewee 2, 2019)

"Sufficient information is not available at institutions. They look at the transactions that were completed within their banks only. Each bank is doing this individually and not collectively. Banks can't see the transactions that other banks see" (Interviewee 5, 2019)

In large banks, the analysis of cases also does not even cross the barriers of departments.

"Most of the transaction monitoring systems are looking at individual transactions rather than at the entity level. They look at the transaction level but not at the entity level. The same entity may have suspicious transactions in different parts of the bank, but the detection mechanisms would capture these suspicious transactions separately. It is compartmentalised" (Interviewee $6,2019)$

The scale of the UK's public-private partnership is limited and not inclusive.

"Partnerships contribute with a small portion of reporting but do not stop the unnecessary reporting that is required by the legislation - JMLIT is a tremendous success, but it is limited. It is a boutique and specialised solution; it should be rebuilt into a more industrial factor type model" (Interviewee 1, 2019)

The mechanisms for voluntary sharing of information between financial institutions are underutilised.

"Despite the fact that the Criminal Finance Act 2017 contains legal provisions to enable privateprivate information sharing, this has not been used yet. The JMLIT and the UKFIU have not been evoking further utilisation of the Criminal Finance Act to expand the reach of information sharing within different private institutions which could have exposure to the same cases or customers.” (Interviewee 4, 2019)

Voluntary sharing is also conditioned to the involvement of the NCA and the existence of a suspicion. There is no point in collaborating with peers after these conditions are met.

"Outside of JMLIT, the NCA needs to be involved for the collaboration between banks to be legal. A suspicion is also required. If a bank, however, already confirms a suspicion, why would the bank bother about collaborating if it can just submit the SAR?" (Interviewee 5, 2019) 
Financial institutions, in reality, avoid assuming that the suspicion condition is met, as they are afraid of not having enough information to support such a claim.

"There is a risk, however, with using the Criminal Finance Act 2017), because financial institutions must have enough information to evidence or satisfy the suspicion threshold. Institutions get nervous about having enough information." (Interviewee 6, 2019)

Most of the opportunities to detect suspicious activity across institutions come before the confirmation of the suspicion.

"Being able to share information that is below suspicion for the purpose of identifying suspicion is what is missing in the CFA." (Interviewee 5, 2019)

There is a need for a central repository where information can be shared across institutions and sectors and more advanced technology applied.

"We should get information from all FIs, NGOs and other industries, anonymise it and put it in a secure environment where it can be explored using advanced technologies." (Interviewee 4, 2019)

\section{$A M L$ is not evolving uniformly across sectors}

The fourth finding was that AML does not progress uniformly across sectors and NFIs have been apart from partnerships and the development of advanced technologies.

The development of advanced technologies have not been developed uniformly across sectors.

"Machine learning is being used in the private sector, but not uniformly. In the public sector the Tech Sprint has been a helpful initiative to leverage these emerging solutions. The Economic Crime Plan has a specific action to promote innovation using technology in the economic crime space - potentially by leveraging the Tech Sprint to other sectors. Although leveraging the Tech Sprint to other sectors has been considered, technology may not be the first problem to be faced by these sectors." (Interviewee 3, 2019)

NFIs do not have enough resources to invest in more sophisticated AML controls.

"In many instances, NFIs are small businesses that do not have a significant number of resources to dedicate to controls which are not part of their core activities. Processing complex guidance, with hundreds of pages, issued by the regulators, is overwhelming for a small institution with limited resources; as a result, many small institutions have a very low level of awareness about AML controls." (Interviewee 8, 2019) 
NFIs have also been apart from partnerships, which prevents them from building a clearer picture of cases.

"Accountants can see where the money went to, but the bank may be able to see where the money went from there. The combination of the accounting plus the bank information could form a much clearer picture.” (Interviewee 7, 2019)

The existing mechanisms used to report suspicious activities are complex and the terminology used is inadequate for NFIs.

"The format of the SAR template is not fit for purpose; it is not multi-sector and is focused on the financial sector. It is off-putting." (Interviewee 8, 2019)

"There is a need to make the SARs template terminology align with the language that the sector uses, instead of the language used by LEAs.” (Interviewee 7, 2019)

\section{LEAs are not guiding FIs to focus resources on relevant cases of investigation}

The fifth finding relates to the fact that LEAs have not been stopping low-utility reports and are not guiding Financial Institutions' resources to focus on relevant cases of investigation.

"The public sector does not have the agility to coordinate itself and provide guidance to focus or stop activity. They should provide guidance on what not to report. They can either increase resources or stop low-utility reporting. LEAs cannot articulate (feedback on) SARs on a case by case basis. The NCA technology does not give this granularity; it is not only feedback, but also guidance." (Interviewee 2, 2019)

Due to the lack of proper guidance, FIs are left to suppose what the LEAs need.

"How to get meaningful intelligence to the LEAs in a timely manner so that they can take steps to deal with it. How to pull data at an industry level to apply analytics and allow LEAs, with the required safeguards, to look for what they need to look for, rather than having the FIs supposing what LEAs need to look for.” (Interviewee 6, 2019)

LEAs currently see SARs as data, not intelligence.

"LEAs use the SARs as a database which is consulted as part of investigations. LEAs don't act on the SAR; they use it as a database. If it is to be used as a database, why not just pull the data?" (Interviewee 6, 2019) 
"LEAs use the SARs database as a proxy for transactions, where they search for supporting information for investigations and sometimes find useful information. The perception that LEAs are encouraging the submissions of fewer SARs with higher quality is not true; most LEAs would say the more the better - they want an easy pool of data." (Interviewee 5, 2019)

If LEAs don't investigate SARs properly, there is no point in creating additional requirements for financial institutions.

"Before creating additional requirements for banks, problems in other critical parts of the process, such as SARs processing, should be resolved. Assuming that $90 \%$ of the SARs are never used, there is no reason for creating additional requirements for banks." (Interviewee 5, 2019)

\section{Incremental adjustments will not improve the effectiveness of the regime}

The sixth finding was that incremental adjustments will not solve the AML regime's ineffectiveness, and a sustainable funding model is needed to fund a major transformation.

The system needs to be reset, and a fresh parallel track is needed to develop a new framework.

"If the financial sector is spending billions on financial crime compliance each year, how is it possible to reset the system so that these resources add actual value?" (Interviewee 1, 2019)

"We should improve what is existent and create a parallel track to develop the future state framework. With the right will, the required transformation would take 3 to 4 years." (Interviewee 6, 2019)

A sustainable funding model is needed to enable a major transformation. Presently, funding is unbalanced between the public and private sectors, and the lack of resources in the public sector have been hindering the transformation of the overall regime.

"The public sector is underfunded. The solution needs to be that for every 10 points that the financial sector spends, the government needs to spend an extra 2 points to develop their side." (Interviewee 1, 2019)

The need for a thorough review of the current regime was reported as indispensable by all participants. They used expressions like "the system is entirely broken", "it is not fit for purpose", "the criminals are winning", and "it just doesn't work", to describe their opinion about the effectiveness of the current regime.

\section{Discussion}


Since the completion of this research, some progress has been made in the UK's ongoing efforts to improve the anti-money laundering regime. The sense of shared ownership across the public and private sectors can be evidenced by the work of new public-private partnerships at a tactical level (for example the response to COVID-related fraud), and at a more strategic level by the Economic Crime Strategic Board (ECSB). The development of proofs of concept about privacy-enhancing analysis techniques and the implementation of some of the Economic Crime Plan's (ECP) actions can also be noted, for example, the new Companies House identity verification requirement and its greater powers to query, investigate and remove false information from its registers.

The actions implemented so far continue to be, however, incremental. It is also unclear the extent to which they have yielded a tangible benefit to the reduction of money laundering. The development of an operational performance measurement system is one of the key areas in the Economic Crime Plan but has not been fully implemented yet. There is a lack of outcome-orientated indicators to assess the impact of changes and the return over the investments made so far. The key question of whether they have improved the AML regime remains unanswered.

This research does not aim to provide a comprehensive list of actions required to address the regime's ineffectiveness. Still, it shed light on actions that could have a more significant impact in a shorter period of time. The three actions to follow target the core of the issues that undermine the regime.

First, financial institutions must be able to apply the risk-based approach effectively, and the regulators should recognise that FIs do not feel supported by them to do so. Many of the existing financial crime controls are driven by "tick-box" compliance with the regulations - the fear of being judged by the regulators for not doing enough to tackle risks leads FIs to be over-cautious. Regulators continue to require and focus on traditional controls and do little to encourage FIs to be innovative or to support them to develop more effective risk-based solutions. Transaction monitoring is an example of this; despite its well-known ineffectiveness level, it is stringently required by the regulators. Without a clear position by the regulator's supervisors as to whether they would consider the replacement of old techniques compliant, FIs will continue to spend large amounts on ineffective controls. The regulatory risk associated with the implementation of new techniques that have not been approved, at least in principle, by the Regulator is simply unaffordable for FIs. The regulators' initiatives to stimulate the development of emerging technologies such as TechSprints are helpful, but they will not change the regime if the use cases demonstrated during the events are not converted into real controls.

Second, the advent of partnerships started to close a long-standing loophole in the regime and allows organisations to perform cross-institutional analysis of money laundering cases. These partnerships, however, continue to be unscalable and not inclusive of all sectors. To address these issues, a number of proofs-of-concept are being developed to explore solutions that can unlock the exchange of 
information across organisations at scale without breaching data protection regulations. The modification made by the Criminal Finance Act of 2017 to the Proceeds of Crime Act (POCA) allowed peer-to-peer sharing of information related to financial crime between FIs, but it conditioned this to the involvement of the National Crime Agency (NCA) and to the presence of a suspicion. However, to improve its ability to detect money laundering cases, FIs need to exchange information below the suspicion. If a suspicion is already confirmed, why would FIs share information? If a suspicion is confirmed, FIs must report. Furthermore, without harmonising customer and transactional data across institutions, the onboarding process for technology solutions to exchange information at scale will be challenging. Before any of this can be applied, further work needs to be done to address the challenges of information-sharing set in the Economic Crime Plan.

Third, law enforcement agencies need to guide financial institutions to stop producing reports that do not trigger an investigation. Less than $3 \%$ of the suspicious activity reports filed to the financial intelligence units are of immediate value for investigations, which means that $97 \%$ of the effort placed by financial institutions in producing these reports are unlikely to lead to any enforcement action. This is aggravated by the "tick-box" compliance approach referred to above which contributes to the maintenance of the current quantity-over-quality approach. Without clearer tactical and strategic guidance from law enforcement agencies on the high-risk financial crime threats, financial institutions will continue to waste resources by filing unproductive reports, and the financial intelligence units will continue to be overwhelmed and miss cases that are genuinely suspicious and require investigation. The regime needs to shift from silos of excellence to a collective approach, where public and private organisations target collective high-risk threats of financial crime. Filing and investigating suspicious activity reports are crucial steps of the AML process. If these steps are not targeted at prioritised highrisk threats and exhaustively completed, the system will, in many instances, fail.

Most fundamental of all the areas in need of change is the creation of an appropriate and sustainable funding model. HM Treasury has announced that it intends to raise $£ 100 \mathrm{~m}$ a year through an "economic crime levy" on the AML-regulated sector. With financial institutions already spending billions of pounds in anti-money laundering controls, this can only increase the already high cost of compliance and contribute to a more imbalanced funding distribution between the public and private sectors. This will go some way to funding the reform needed, but it will not be enough in its own right, and it is unclear how much public money will be available to add to the pot as the economy recovers from the impacts of the COVID-19 pandemic. The levy can make a big difference if used to drive genuine reform, but not be allowed to fund, for example, extra police resources at the expense of improved technology or investment in improving the regulatory or legal landscape. With contractions in economies and increased public debt, higher expectations will be placed over public and private spend. Shifting resources from processes that currently focus on defensive reporting and traditionally ineffective 
controls into more collaborative and technology-led solutions is likely to become the only possible path to follow if we are to improve the effectiveness of the regime in the near future.

\section{Limitations of research}

This research has two limitations. First, given that only a few practitioners in the industry have the knowledge and expertise to discuss the topic at a strategic level, the number of participants was limited to eight. Second, no one from the regulator participated in the research. Engaging with regulators proved to be very difficult. Two representatives were invited but did not agree to participate.

\section{Conclusions}

This research adds to the growing corpus of research showing that the UK's anti-money laundering regime is ineffective and needs reform. The ongoing initiatives are incremental and are not driving the transformation required to improve the regime's effectiveness seriously. FIs must be able to apply the risk-based approach effectively; regulators and FIs need to work together to increase the adoption of advanced technology; LEAs need to provide tactical and strategic intelligence to drive the FIs's focus to quality over quantity on reports, and partnerships must be scaled to include all relevant institutions and sectors. More broadly, public and private organisations need to shift from silos and adopt a more collective approach to target collective high-risk economic crime threats. A sustainable funding plan also needs to be established across the public and private sectors to ensure that the required transformation happens quickly. Despite all the spending so far, the existing regime continues to be unfit for purpose.

\section{References}

Balani, H. (2019), “Assessing the introduction of anti-money laundering regulations on bank stock valuation: an empirical analysis", Journal of Money Laundering, Vol. 22 No. 1, pp.76-88. https://doi.org/10.1108/JMLC-03-2018-0021

BBA (2016), "Response to cutting red tape review: the effectiveness of the UK's AML regime: executive summary", available at: https://www.bba.org.uk/policy/bbaconsultationresponses/bba-response-to-cutting-red-tape-review-effectiveness-of-the-uks-aml-regime (accessed 15 September 2019).

Burns, C. (2020), “\$8.14 billion of AML fines handed out in 2019, with USA and UK leading the charge", available at: https://www.encompasscorporation.com/blog/encompass-aml-penaltyanalysis-2019/ (accessed 27 August 2020) 
Delle-Case, A. and Bailey, N. (2018), Machine Learning in Anti-Money Laundering - Summary Report, Institute of International Finance, Washington, DC.

European Police Office (2016), "Does crime still pay? Criminal asset recovery in the EU", available at:

https://www.europol.europa.eu/sites/default/files/documents/criminal_asset_recovery_in_the_ eu_web_version.pdf (accessed 27 August 2020)

FATF (2018), “Anti-money laundering and counter-terrorist financing measures - United Kingdom: mutual evaluation report", available at: http://www.fatfgafi.org/publications/mutualevaluations/documents/mer-united-kingdom2018.html (accessed 11 June 2020)

Fell, E., James, O., Dienes, H., Shah, N. and Grimshaw, J. (2019), Understanding Organised Crime 2015/16: Estimating the Scale and the Social and Economic Costs, Second edition, Crown, London, UK.

Geiger, H. and Wuensch, O. (2007), “The fight against money laundering: an economic analysis of a cost-benefit paradoxon”, Journal of Money Laundering Control, Vol. 10 No. 1, pp.91-105. https://doi.org/10.1108/13685200710721881

Home Office (2017), "Economic crime factsheet", available at: https://homeofficemedia.blog.gov.uk/2017/12/11/economic-crime-factsheet/

Hopkins, M. and Shelton, N. (2019), "Identifying money laundering risk in the United Kingdom: observations from national risk assessments and a proposed alternative methodology", European Journal on Criminal Policy and Research, Vol. 25, pp.63-82. https://doi.org/10.1007/s10610-018-9390-5

Huang, J.Y. (2015), "Effectiveness of US anti-money laundering regulations and HSBC case study", Journal of Money Laundering Control, Vol. 18 No. 4, pp.525-532. https://doi.org/10.1108/JMLC-05-2015-0018

Bowers, Simon (2020), “'Everyone is doing badly', anti-money laundering czar warns”, International Consortium of Investigative Journalists, available at: https://www.icij.org/investigations/panama-papers/everyone-is-doing-badly-anti-moneylaundering-czar-warns/ (accessed 24 April 2021). 
Jakobi, A.P. (2018), "Governing illicit finance in transnational security spaces: the FATF and antimoney laundering", Crime, Law and Social Change, Vol. 69, pp.173-190. https://doi.org/10.1007/s10611-017-9750-y

Kang, S. (2018), "Rethinking the global anti-money laundering regulations to deter corruption", International and Comparative Law Quarterly, Vol. 67 No. 3, pp.695-720. https://doi.org/10.1017/S0020589318000106

Levi, M., Reuter, P. and Halliday, T. (2018), "Can the AML system be evaluated without better data?", Crime, Law and Social Change, Vol. 69, pp.307-328. https://doi.org/10.1007/s10611017-9757-4

Maxwell, N. J. (2019), Expanding the Capability of Financial Information-Sharing Partnerships, Royal United Services Institute, London, UK.

McGarvey, R. (2013), "Report: Aite questions effectiveness of AML”, available at: https://www.cutimes.com/2013/06/19/report-aite-questions-effectiveness-of$\mathrm{aml} /$ ?slreturn=20210319110427 (accessed 14 July 2020)

McGowan, J. (2017), "Under the spotlight: innovative vendors in financial crime case management technology", available at: https://www.celent.com/insights/358053968 (accessed 27 August 2020)

Moiseienko, A. and Keatinge, T. (2019), The Scale of Money Laundering, Royal United Services Institute, London, UK.

Office for National Statistics (2021), "Gross domestic product: chained volume measures: seasonally adjusted £m", available at: https://www.ons.gov.uk/economy/grossdomesticproductgdp/timeseries/abmi/pn2 (accessed 24 April 2021)

Pol, R.F. (2018), "Uncomfortable truths? ML=BS and AML= BS",, Journal of Financial Crime, Vol. 25 No. 2, pp.294-308. https://doi.org/10.1108/JFC-08-2017-0071

Redhead, M. (2019), Deep Impact? Refocusing the Anti-Money Laundering Model on Evidence and Outcomes, Royal United Services Institute, London, UK.

Turkington, M. (2019), The Effectiveness of Private Sector Engagement in International Financial Crime Countermeasures, La Trobe University, Victoria, Australia, available at: http://hdl.handle.net/1959.9/567957 (accessed 17 December 2019). 
United Nations Office on Drugs and Crime (2011), Estimating Illicit Financial Flows Resulting From Drug Trafficking and Other Transnational Organized Crimes: Research Report. United Nations Office on Drugs and Crime, Vienna, Austria. 